\title{
Systematic Approach to
} the Development,

Evolution, and

Effectiveness of

Integrated Product

Development Teams

(IPDTs)

\section{INCOSE 2011}

U.S. Department of Energy

National Laboratory

operated by

Battelle Energy Alliance

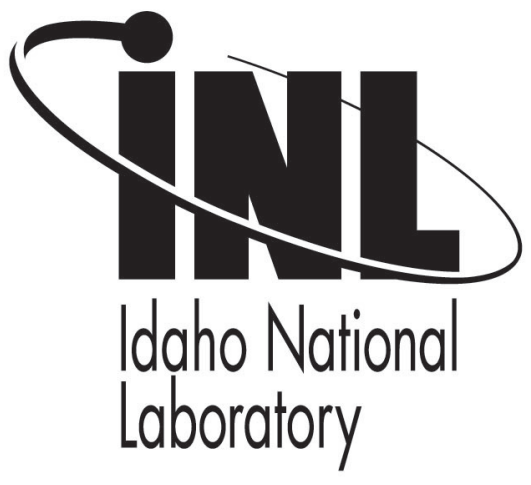

Margie Jeffs

R. Douglas Hamelin

\author{
June 2011
}

This is a preprint of a paper intended for publication in a journal or proceedings. Since changes may be made before publication, this preprint should not be cited or reproduced without permission of the author. This document was prepared as an account of work sponsored by an agency of the United States Government. Neither the United States Government nor any agency thereof, or any of their employees, makes any warranty, expressed or implied, or assumes any legal liability or responsibility for any third party's use, or the results of such use, of any information, apparatus, product or process disclosed in this report, or represents that its use by such third party would not infringe privately owned rights. The views expressed in this paper are not necessarily those of the United States Government or the sponsoring agency. 


\title{
Systematic Approach to the Development, Evolution, and Effectiveness of Integrated Product Development Teams (IPDTs)
}

\author{
Margie Jeffs \\ Idaho National Laboratory \\ PO Box 1625, MS 3780 \\ Idaho Falls, ID 83415-3780 \\ (208) 526-8433 \\ margie.jeffs@inl.gov
}

\author{
R. Douglas Hamelin \\ Idaho National Laboratory \\ PO Box 1625, MS 3780 \\ Idaho Falls, ID 83415-3780 \\ (208) 526-2337 \\ douglas.hamelin@inl.gov
}

Copyright $(\mathcal{C} 2011$ by Battelle Energy Alliance, LLC. Published and used by INCOSE with permission.

\begin{abstract}
Integrated Product Development Teams (IPDT) are a key component of any systems engineering (SE) application, but since they are formed primarily from technical considerations, many IPDTs are far less productive than they otherwise could be. By recognizing specific personality types and skill sets, a random group of "technical" individuals can be structured to become a highly effective team capable of delivering much more than the sum of its members.
\end{abstract}

\section{Introduction}

Integrated Product Development Teams (IPDT) are a key component of any systems engineering (SE) application, but they are generally not used as effectively as they could be. Team members are usually chosen to be part of the IPDT because they happen to be the ones who are currently available, they have the most expertise in a technical discipline and have the technical skills or knowledge that is needed, are a stakeholder in the outcome or product, or because of who they are or the position they hold in the company. Not much consideration is given to how or even if team members can work together. Two critical issues need to be considered when it comes to forming a team. First is the technical expertise that is required, and systems engineers are pretty adept at selecting these types of team members. The other is the behavioral and inter-relational competence that is necessary for the team to get along and work together. Both aspects are needed to form an effective, high-performing team.

Since most IPDTs are formed primarily from technical considerations, many IPDTs are far less productive than they otherwise could be. By recognizing specific personality types and skill sets and by monitoring and guiding team development, a random group of technical individuals can be structured to become a highly effective team capable of delivering much more than the sum of its members. ${ }^{1}$

Definition of Effective Teams. According to Katzenbach and Smith, "A team is a small number of people with complementary skills who are committed to a common purpose, performance goals, and approach for which they hold themselves mutually accountable [italics added]." " Notice that none of these stated characteristics address "technical" ability or expertise. Truly effective teams take this definition above one step further by working synergistically to maximize performance. Synergy is when the whole is greater than the sum of the parts. To achieve such levels, an effective team will need trust, open and honest communication, mutual respect, common goals, shared responsibility, a willingness to 
collaborate and capitalize on each member's strengths while supporting individual weaknesses, and a shared understanding of the "big picture." These all help create synergy.

Let's look at an example of synergy in nature. A tiger is a magnificent and majestic animal. It achieves many great things, but it is not the king of the cats - the lion is. Why is that the case? The tiger is a loner that works, hunts, and lives basically alone. The lion, however, belongs to a pride and has learned to live in a community and capitalize on each of the member's strengths while supporting each member's weaknesses. Hence, lions have learned that strength lies in prides, communities, and teams. The lion and the pride effectively represent many of the team qualities listed above, namely, they share responsibilities and common goals, support each other, work and live in unity, communicate effectively, and have a sense of mutual respect and trust.

\section{Team Dynamics}

Whenever a team is created, team dynamics immediately exists. By understanding team dynamics, a more effective team can be assembled and maintained. Team dynamics are defined as the "unseen forces that operate in a team between different people or groups. Team dynamics can strongly influence how a team reacts, behaves or performs, and the effects of team dynamics are often very complex." These unseen forces can include, but are not limited to:

- Personality styles (e.g., including or excluding people, egos) (Belbin Research)

- Team Roles and Responsibilities (Belbin Research)

- Office or conference room layout and conditions

- Tools and technologies (e.g., email, bulletin board, information pool enabling hidden communication)

- Organizational culture (e.g., organizational status, us vs. them attitudes, employee groups or cliques)

- Processes, methodologies, and procedures

To manage team dynamics effectively, systems engineers need to recognize the "natural forces" at work and determine whether those forces are aiding or hindering team progress. Necessary interventions can then be implemented to ensure that the effects of those dynamics are more positive. ${ }^{3}$ In addition, all teams need:

- A clearly defined mission and shared sense of purpose

- Meaningful performance goals for each aspect of the mission

- Specific deliverables or outcomes that will be expected

- Agreed upon approaches and processes that ensure team members can accomplish tasks efficiently and effectively

- Mutual support for the common mission

- A commitment to individual responsibility and to doing their part in accomplishing tasks

- A balanced mix of skills, experience, and expertise to tackle emerging challenges. ${ }^{4}$

Each team member is directly responsible for the entire team's successes and failures. ${ }^{5}$ Clearly defining individual roles and responsibilities helps to lessen confusion and gives the team anchor points to draw upon when conflicts arise. It also helps to identify any known or potential issues and concerns so that these can be addressed while they are still manageable. 


\section{Understanding Team Dynamics - "Thinking Style Tools"}

Many tools and resources are available to help systems engineers and other team leaders understand the differences that contribute to team dynamics. The benefit of using these "thinking style" tools to promote effective teams lies in the ability to establish a "whole brain" approach based on the strengths of the strengths and thought processes of the individual team members.

Herrmann Brain Dominance Instrument. One of these tools is the Herrmann Brain Dominance Instrument (HBDI), created by Ned Herrmann in late 1970s. In the early 1970s, Sperry introduced the commonly known right brain/left brain model of thinking. Shortly after Sperry's theory, McLean introduced the limbic portion of the brain as a contributor to brain thinking and motivation. Ned Herrmann took both models and introduced his version of thinking preferences. Using both the right and left sides of the cerebral and left and right sides of the limbic of the brain for his model, Herrmann developed a metaphor approach with color quadrants to represent all four portions of the brain, as illustrated in Figure 1. Each quadrant represents different thinking preferences in each of us and consists of different strengths, as illustrated in Figure $2 .^{6}$

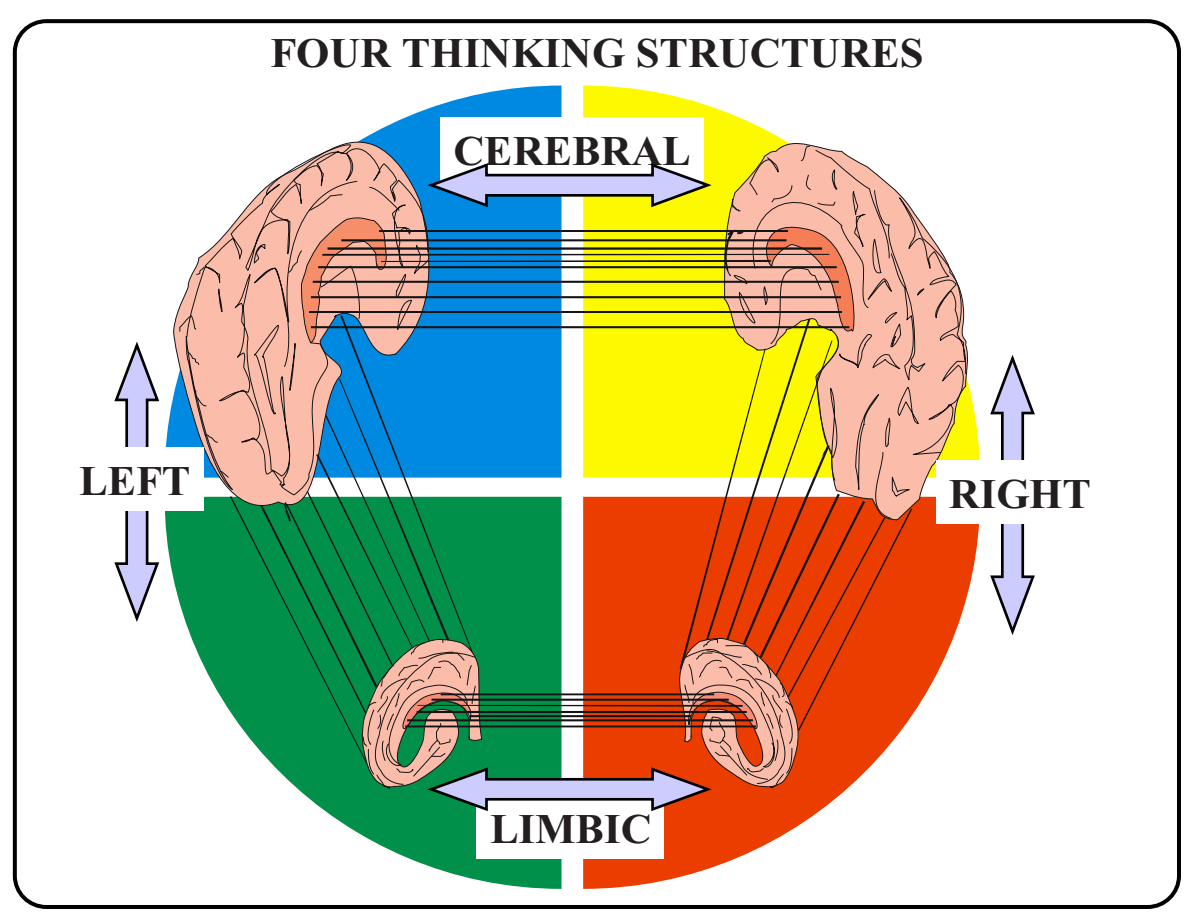

Figure 1. Ned Herrmann metaphor of the Four Thinking Structures of the brain 


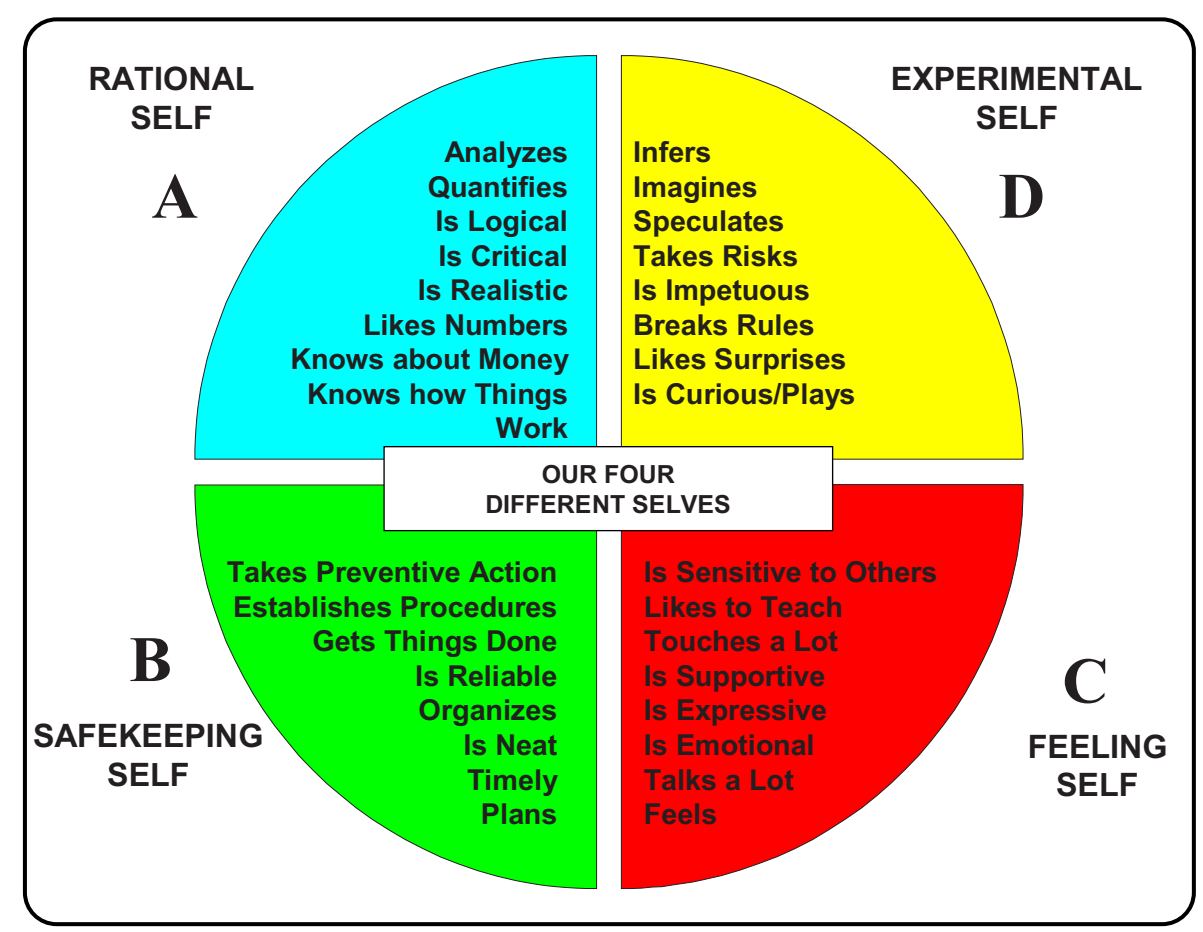

Figure 2. HBDI Four Quadrant Thinking Styles

The four quadrants (our preferential thought patterns) express in each person at different levels: low, middle, strong, and very strong. If a person measures low in a particular quadrant, that person will avoid the preferences associated with that quadrant, if at all possible. If a person measures middle, that person is comfortable working within those thought preferences and will use them as needed. If a person measures strong, the associated preferences are considered to be "dominant" preferences and most likely that person's primary way of thinking. If a person measures very strong, the associated preferences are considered "highly dominant" and can often be over expressed. A person can be dominant in one or more quadrants. Understanding our own, as well as other's, thinking preferences contributes to collaboration in effective IPDTs by identifying and emphasizing the strengths of the individual team members.

Understanding that HBDI is a formal scientific assessments based on parameters developed by their years of experience, individual and team assessments can be completed through HBDI (for a fee) to gain a more thorough understanding of thinking styles and preferences of perspective team members. Conversely, similar assessments can be conducted informally through discussions between the systems engineer and the program manager based on their personal experiences and knowledge of the characteristics of candidate team members. Ultimately, the decision as to whom should be on the team and why rests with the program manager with input from the systems engineer. Part of this decision should include how those members will most likely progress through Tuckman's Stages of Team Development, which will be discussed later in this paper.

Belbin Team Role Theory. Dr. Meredith Belbin has conducted extensive research on the unique roles and responsibilities common across a wide range of effective teams. Belbin believes that teams, not individuals, drive results. In her research, she has discovered that effective teams have nine common roles: Plant, Resource Investigator, Co-ordinator, Shaper, 
Monitor/Evaluator, Teamworker, Implementer, Completer/Finisher, and Specialist. A team member may hold one or more roles. Each role has its own weaknesses and strengths, as illustrated in Figure $3 .^{7}$

\section{THE NINE TEAM ROLES}

\begin{tabular}{|c|c|c|}
\hline & CONTRIBUTIONS & ALLOWABLE WEAKNESSES \\
\hline PLANT & $\begin{array}{l}\text { Creative, imaginative, } \\
\text { unorthodox. Solves difficult } \\
\text { problems. }\end{array}$ & $\begin{array}{l}\text { Ignores incidentals. Too } \\
\text { preoccupied to communicate } \\
\text { effectively. }\end{array}$ \\
\hline $\begin{array}{l}\text { RESOURCE } \\
\text { INVESTIGATOR }\end{array}$ & $\begin{array}{l}\text { Extrovert, enthusiastic, } \\
\text { communicative. Explores } \\
\text { opportunities. Develops } \\
\text { contacts. }\end{array}$ & $\begin{array}{l}\text { Over-optimistic. Loses interest } \\
\text { once initial enthusiasm has } \\
\text { passed. }\end{array}$ \\
\hline CO-ORDINATOR & $\begin{array}{l}\text { Mature, confident, a good } \\
\text { chairperson. Clarifies goals, } \\
\text { promotes decision-making, } \\
\text { delegates well. }\end{array}$ & $\begin{array}{l}\text { Can be seen as manipulative. } \\
\text { Offloads personal work. }\end{array}$ \\
\hline SHAPER & $\begin{array}{l}\text { Challenging, dynamic, thrives } \\
\text { on pressure. The drive } \\
\text { and courage to overcome } \\
\text { obstacles. }\end{array}$ & $\begin{array}{l}\text { Prone to provocation. Offends } \\
\text { people's feelings. }\end{array}$ \\
\hline $\begin{array}{l}\text { MONITOR } \\
\text { EVALUATOR }\end{array}$ & $\begin{array}{l}\text { Sober, strategic and } \\
\text { discerning. Sees all options. } \\
\text { Judges accurately. }\end{array}$ & $\begin{array}{l}\text { Lacks drive and ability to } \\
\text { inspire others. }\end{array}$ \\
\hline TEAMWORKER & $\begin{array}{l}\text { Co-operative, mild, perceptive } \\
\text { and diplomatic. Listens, builds, } \\
\text { averts friction. }\end{array}$ & Indecisive in crunch situations. \\
\hline IMPLEMENTER & $\begin{array}{l}\text { Disciplined, reliable, } \\
\text { conservative and efficient. } \\
\text { Turns ideas into practical } \\
\text { actions. }\end{array}$ & $\begin{array}{l}\text { Somewhat inflexible. Slow to } \\
\text { respond to new possibilities. }\end{array}$ \\
\hline $\begin{array}{l}\text { COMPLETER } \\
\text { FINISHER }\end{array}$ & $\begin{array}{l}\text { Painstaking, conscientious, } \\
\text { anxious. Searches out errors } \\
\text { and omissions. Delivers on } \\
\text { time. }\end{array}$ & $\begin{array}{l}\text { Inclined to worry unduly. } \\
\text { Reluctant to delegate. }\end{array}$ \\
\hline SPECIALIST & $\begin{array}{l}\text { Single-minded, self-starting, } \\
\text { dedicated. Provides knowledge } \\
\text { and skills in rare supply. }\end{array}$ & $\begin{array}{l}\text { Contributes on only a narrow } \\
\text { front. Dwells on technicalities. }\end{array}$ \\
\hline
\end{tabular}

Figure 3. Belbin's Nine Team Roles

As stated in the introduction to HBDI, each person brings their own unique set of strengths and weaknesses to bear on the team. According to Belbin, the behavioral skills in the nine roles shown in Figure 3 keep the team balanced. Some team members may have stronger people skills, others may have stronger thinking or creative skills, while still others may have stronger planning, action, or task skills. A well-balanced team needs all of these behavioral skills and corresponding roles to be effective. Knowing which team member has which skills to add to the team and then defining corresponding roles for each member at the beginning of the team formation keeps the team focused, balanced, and moving forward. If necessary, a team member could hold more than one role simultaneously. 
Belbin states that team roles and skills may overlap. Keeping that in mind, each role still has varying strengths to aid at each project phase. For example, the roles necessary for focusing on goals belong to the Shapers and Co-ordinators and come into play early in the project life cycle. If the team needs to generate new ideas, the Plants and Resource Investigators offer the best set of skills. Monitor/Evaluators and Specialists are most adept at forming plans and schedules, while Resource Investigators and Team Workers are invaluable for making and maintaining contacts. Implementers and Co-ordinators typically keep the team organized, and for follow through, the Implementers and Completer/Finishers have the best skills for the job. If there are voids or surpluses in any of the team roles, the team will not be as balanced. Understanding what the team members bring to the table will make it easier to avoid capability gaps and helps the team function at its best.

\section{Evolution of Effective Teams}

Recognizing which developmental and evolutionary stage a team is in gives leaders a much better idea of why people are acting the way they are and how to move the team forward more effectively and achieve a high level of performance. A sequential stage view of team development offers several valuable insights:

- The stages enable team members to anticipate what the team is likely to go through. This will prevent them from being surprised or depressed by various events.

- The stages enable team leaders to use appropriate strategies to smooth the progress of a team as it evolves.

- Different teams may proceed through different stages at different speeds, a process that can be affected by the fact that team members may individually have varying rates of progress. Members of a team should avoid making self fulfilling prophecies about how long each stage will last.

- A team may sometimes regress to an earlier stage. For example, team members may return to a previous stage if they discover that the team's mission or membership has changed.

- It is possible for a team to be in different stages at the same time with respect to different aspects of its mission. ${ }^{10}$

- The most predominantly referred to and most widely recognized group development model in organizational literature is the Forming - Storming - Norming - Performing model developed by Bruce Tuckman in 1965. Tuckman maintained that these stages are all necessary and inevitable for the team to grow, face up to challenges, tackle problems, find solutions, plan work, and deliver results. ${ }^{8,9}$ Leaders gauge a team's progress through the stages of development by assessing two key factors: (1) the level of enthusiasm, motivation, and team moral, and (2) the skill or level of performance of the team as a group (not as individuals).

It was stated earlier that the ultimate decision regarding team membership lies with the program manager. Understanding team dynamics and the stages a team moves through helps the program manager be more aware of how individual team members will work together and where potential conflicts may arise. Having this awareness helps program managers prepare for and mitigate those conflicts if they happen. In the event that a team cannot reach a consensus on a decision (which is the preferred approach), the project manager then becomes 
responsible for making decisions so the team can move forward. A brief description of the stages of team development and the implications those stages have on IPDTs follows.

Forming. Every team goes through the Forming stage; it's inevitable. When forming, team members are usually excited and optimistic about the new project, and they often show pride in being selected as a team member. Subsequently, the Forming stage usually comes with high, optimistic, and often unrealistic expectations accompanied by some anxiety about how members will fit in, how much they can trust others, and what demands will be placed on them. ${ }^{10}$ Team energy and effort is typically spent defining the mission, setting objectives, defining responsibilities, and establishing a project schedule with deadlines.

At this stage, the major issues are personal well-being, acceptance, and trust, and individual behaviors are driven by a desire to be accepted by the others, and avoid controversy or conflict. Team members are unclear about norms, roles, goals, and timelines. Serious issues and feelings are generally avoided, and team members focus on being busy with routines, such as team organization, which does what, when to meet, etc. Team members are also gathering information and impressions about each other, and about the scope of the task and how to approach it, often resulting in some degree of suspicion, fear, and anxiety about the work ahead. Team members are usually on their best behavior but very focused on themselves. Mature team members begin to model appropriate behavior even at this early phase. ${ }^{9}$

Because the team generally lacks the collective "team-based" skills needed to perform effectively and meet project objectives, team members tend to place high dependence on the leadership figure for purpose and direction. The team meets and learns about the opportunity and challenges, and then agrees on goals and begins to tackle the tasks, but the avoidance of conflict and threat means that not much actually gets done. As such, team leaders need to take a directive (i.e., instructive, clarifying, information), rather than supportive (i.e., building or sustaining team moral), leadership approach during this stage by explaining specific details of what needs to be done and what is expected of team members. Team leaders must be careful that they give the team sufficient time to properly form at the beginning of a project by setting objectives, defining responsibilities, and establishing a work plan. ${ }^{9,10,12}$ Artificially rushing the Forming process will result in the team reverting back to the Forming stage at a later time to complete this stage of development.

IPDT Implications. Because of the highly "technical" focus of SE work, many IPDTs do not take the time necessary for a team to come together as a group, regardless of the tasks at hand. Mission, objectives, roles and responsibilities, and schedules are usually developed by the project manager or a select group of individuals without involving "technical" team members in those decisions. As a result, IPDTs often do not have the camaraderie or level of project buy-in needed to move the project forward. Systems engineers need to carefully plan for and include IPDT members in upfront Forming activities to ensure project buy-in and establish a firm basis for members to work together in achieving agreed upon objectives.

Storming. Storming is rarely pleasant; it can be contentious, unpleasant, and even painful to members of the team who are averse to conflict. Nonetheless, it is a normal and necessary part of a team's development and evolution. Every team experiences Storming; in fact, even teams that have been together for a long time "storm" as they develop new skills or work to achieve a new goal. It's almost always going to happen. When it does, motivation and 
enthusiasm drop significantly while the collective "team" skills are still not at the level needed for the team to function smoothly.

The primary issues in this stage concern power, control, and conflict, and without the tolerance and patience of each team member, the team will fail. Team members usually experience sharp fluctuations in attitude and often become argumentative and defensive. The work may be more demanding than anyone expected, and team members often becoming discouraged. ${ }^{11}$ They start blaming each other when things go wrong and could be disappointed in themselves as they experience a discrepancy between their initial expectations and the evolving reality. During the Storming stage, team members may:

- Resist task demands or suggestions for improvement from other members

- Have doubts about the work plan's ability to succeed

- Compete for resources or recognition

- Resent that others are not listening to their ideas

- Want to change the team's objectives

- Raise issues of ethics or politics that need to be addressed

- Believe they are doing more than their share of the work. ${ }^{12}$

Subsequently, team energy and effort is typically spent handling disagreements, sensing tension and anxiety, doubting the leadership, addressing conflict, feeling uncertain and frustrated, etc.

When a team is Storming, leaders shouldn't become too upset or frustrated, because a period of conflict is normal soon after a team is formed. The important thing is to not let small conflicts or disagreements sidetrack the project. ${ }^{12}$ During this stage, team leaders still need to be directive in their guidance of decision-making and professional behavior, but because of growing conflict among team members, leaders need to take a more supportive (i.e., encouraging, motivating, uplifting) leadership approach to addressing team concerns. Because of this shift in leadership style, the group will most often resolve their differences and group members will be able to participate with one another more comfortably and without feeling that they are being judged in any way. ${ }^{9}$

In some cases, Storming can be resolved quickly. In others, the team never leaves this stage. ${ }^{8,9,10,11}$ In fact, if a team is going to get stuck in its progress, it will most likely be during the Storming stage. This can become destructive to the team and will further lower motivation if allowed to get out of control. ${ }^{9,10}$ Many teams mistakenly view the natural onset of Storming as a sign of unavoidable failure, and rather than work through the issues and challenges, they simply give up and quit. A significant number of divorces and failed business ventures can be attributed to the fact that team got stuck in the Storming stage.

In these situations, the team leader often assumes the increased responsibility of engaging team members in a catalytic event, so to speak, that changes their individual paradigms and allows them to move beyond their conflicts with a different understanding of what can and needs to be accomplished. This concept is illustrated in the feature film Remember the Titans. $^{13}$ In this real-life account, a new football team is formed by the merger of two high schools, one predominantly black and the other predominantly white. The racial tensions at 
the time make this an extremely volatile situation, particularly given the administration's selection of Herman Boone, a black man, as head coach. The team spends several weeks together at Gettysburg College preparing for the upcoming season. Like most teams, they progress through Forming and soon find themselves unable to move on because of long held tensions and prejudices. Despite efforts by the coaching staff to not let it "get out of control," the team is stuck and on the verge of destruction. Rather than give up, Coach Boone "creates" a catalytic event by waking the players very early in the morning and leading them on a long run through the battlefields of Gettysburg. Arriving at the Gettysburg cemetery just as the mist is lifting off of the grave stones, he talks about the thousands of lives given by both black and white soldiers in their fight for unity. He tells the players, his team members, that the soldiers' prejudicial differences almost destroyed the nation, and that those same differences will destroy their team if they can't learn to rise above them. That single event changed the paradigms of the individual players and of the team as a whole, and they went on to an undefeated season and a state championship.

Each team is different, and as such, each leader carries the responsibility to create the catalytic event, when needed, that best resonates with the team members - one that touches the unique concerns and characteristics of the team. The critical point here is to not give up. Ultimately, the maturity of some team members usually determines whether the team will ever move out of this stage, but there is always a way to move the team forward; the leader just has to find it.

IPDT Implications. Due to project-imposed time constraints, it is tempting to try and "avoid" Storming or to "reorganize" a Storming team with new members to eliminate any conflicts. This is absolutely the worst course of action a systems engineer can take when working with a "storming" IPDT. Two results support this claim. First, who don't work out their differences and find solutions to their problems, though they may appear to "perform" for a time, will allow those differences to fester and return to them later, usually at times of project crisis and looming deadlines. Second, each time a team is reorganized, the members are forced back into the Forming stage, with all of the baggage and concerns associated with initial team assemble. The only difference is that this time their level of motivation and enthusiasm will not be as high. Ultimately, this "new" team will naturally find itself Storming with similar or more severe conflicts that previously experienced.

It is in the best interest of the project and of all parties involved for systems engineers and IPDT leaders to closely monitor team interactions until the storming reaches a point that necessitates intervention. If done effectively, the team emerging from that intervention will be empowered to "Norm" to a common set of objectives and approaches that will drive high performance.

Norming. At some point, the team will enter the Norming stage. In this stage, team members begin to accept their roles and responsibilities and to adjust their behavior toward each other as they develop habits that make teamwork seem more natural and fluid. Norming comes from the word normal and implies everyone working together with both their enthusiasm and collective skills increasing and aligning to match the work to be done. Team members often work through this stage by agreeing on rules, values, professional behavior, shared methods, working tools, and even taboos. As team members get to know and accept each other better, their views of each other begin to change; they begin to trust each other, and a sense of team unity develops. As a result, criticism becomes increasingly open and constructive as team 
members strive to achieve the project's mission and objectives. ${ }^{9,11,12}$ Team energy and effort is typically spent Forming consensus, refining the team's objectives and outcomes, solidifying team roles, and focusing group members around the project mission.

Issues at this stage concern the sharing of control and avoidance of conflict. Because the newly developed feelings of trust and cohesion are fragile, team members tend to avoid direct conflict for fear of losing the positive climate. This reluctance to deal with conflict can slow progress and lead to less effective decisions for a while. In some cases, teams may even lose their creativity if the Norming behaviors become too strong and begin to stifle healthy dissent. $^{9,10}$

As the issues and conflicts encountered in the Storming stage are addressed and resolved, morale begins to rise and creativity returns. Task accomplishment and technical skills increase, which contributes to a positive, enthusiastic attitude and environment and to increased clarity and commitment to purpose, values, norms, roles, and goals. Trust and concern grow as communication becomes more open and task-oriented, and team member show an increased willingness to share responsibility and control. Team members value the differences among themselves; in essence, the team starts thinking in terms of "we" rather than "I." They are getting used to the ways they will work together and accomplish tasks, and they know what they have to do in order to move forward. ${ }^{10,11}$

During this stage, team leaders tend to be participative more than in the earlier stages, and team members can be expected to take more responsibility for making decisions and for their professional behavior. ${ }^{9}$ The key point here is that the leader is involved enough to offer clear and immediate correction or clarification, as needed, without disrupting the growing autonomy of the team. The primary concern is that the leader not get in the way and stifle the team's attempts to try things on their own or exercise the skills and abilities that are starting to emerge.

IPDT Implications. Many leaders at this stage of a team's development begin to feel like they are losing control because the team is starting to move forward without them. The temptation is to try to regain control by imposing a more directive leadership approach, such as those models employed during the Forming and Storming stages. When this happens, the leader inadvertently pulls the team back to the corresponding earlier stage of development, and all forward progress is stopped. Systems engineers and team leaders need to trust that they have given their teams the skills necessary to succeed and let them begin using them on their own.

Systems engineers and team leaders should also be careful to take time and to revise team expectations and recognize each member's role in the team, as well as their strengths and weaknesses. Some members may begin to feel threatened by the amount of responsibility they have been given and, in an attempt to resist the mounting pressure, revert to Storming. It is both normal and healthy for teams to go back and forth between Storming and Norming as team members work through personal interactions and accept their individual roles and responsibilities. That's all part of the process of team building. When leaders know it can happen, they can more effectively help the team work through it and keep moving ahead. , 11,12 $^{2}$

Performing. When teams reach the Performing phase, they are able to function as a unit as they find ways to get the job done smoothly and effectively without inappropriate conflict or 
the need for external supervision. They have developed the skills they need to achieve the goals that challenge them and they are working together well and feeling good about the team's progress. They resolving difficulties and finding effective ways to get things done without supervision, and they are confident in their ability to perform tasks and overcome obstacles. They have a sense of pride in belonging to a successful team, and they enjoy working together. Team members recognize each other's talents and weaknesses and they begin to understand and anticipate each other's needs and capabilities. The trust and respect they have for one another is high, as is their productivity, motivation, and enthusiasm. They are eager to push ahead and achieve all they can. They are Performing. ${ }^{9,11,12}$

The primary focus at this stage is on performance. Purpose, roles, and goals are clear; standards are high; and there is a commitment to not only meeting baseline standards but to continuous improvement. Communication is open and leadership is shared.

A Performing team will still have its ups and downs. Dissent is expected and allowed as long as it is channeled through means acceptable to the team, and mutual respect and trust are the norms. ${ }^{9,10}$ On occasion, the team might even regress back into the Norming or even the Storming stages as new challenges are encountered while completing project tasks. In fact, when a team in the Performing stage starts down the trail toward a fresh goal, sets out to learn a new skill, or has significant changes in its membership, that team will no longer be in the Performing phase. For that new goal, skill, or membership, the team will begin again with Forming, then progress through the Storming and Norming stages, even if only briefly. Eventually, the Performing team regroups and puts the focus back on quality. Many longstanding teams go through these cycles many times as they react to changing circumstances. $^{9,10,12}$

IPDT Implications. systems engineers and leaders of teams in the Performing phase are almost always participative in that they have their own set of roles and responsibilities that they must perform to contribute to the team's success. The team will make most of the necessary decisions and take necessary actions without the need for leader intervention. ${ }^{9}$ In this model, the systems engineer and team leader are available for consultation on an as-needed basis, but the vast majority for work processes and decisions are made and implemented by the team. The primary concern, again, is that the leader has to get out of the way (both literally and figuratively) and let the team perform. Any uninvited intervention can set the team back and negatively impact progress.

When a Team Breaks Up. Several years after Tuckman introduced his four stages of team development, he introduced a fifth stage - Transforming or Adjourning - characterized by ending and closure of the team's existence. There may come a time when a team is disbanded or dramatically reorganized, usually upon completion of project objectives. This may result in sad and awkward feelings and behaviors or in difficulty or and attempt to avoid ending and saying good-bye. If a team is ending or becoming something else, leaders and teams will naturally go through a mourning process because of the ending associations and productivity of the team. When this occurs, teams should make a special effort to celebrate the many successes that the team has enjoyed during their time together. It is also a good idea to review the progress the team has made and its evolution to becoming a highPerforming team. Team members will then be ready to begin the Forming stage with a new team and progress from there. ${ }^{11}$ 
Figure 4 provides a graphical overview of team evolution and the corresponding leadership approaches that foster team development. As shown, the rise and fall of a team's collective motivation and skills have an inverse leadership approach that helps guide team evolution. When teams have a low level of collective skill but a high level of enthusiasm (typical of the Forming stage), the leader makes up for it by providing the technical instruction and direction needed to accomplish project tasks while, at the same time, allowing the team to carry team morale. As motivation drops, the leader assumes the role of cheer leader and morale officer as well. Following the cycle to the end of the model, teams ultimately take control of both their high level of collective skill and their morale, leaving the leader to participate as a team member rather than mediator and coach.

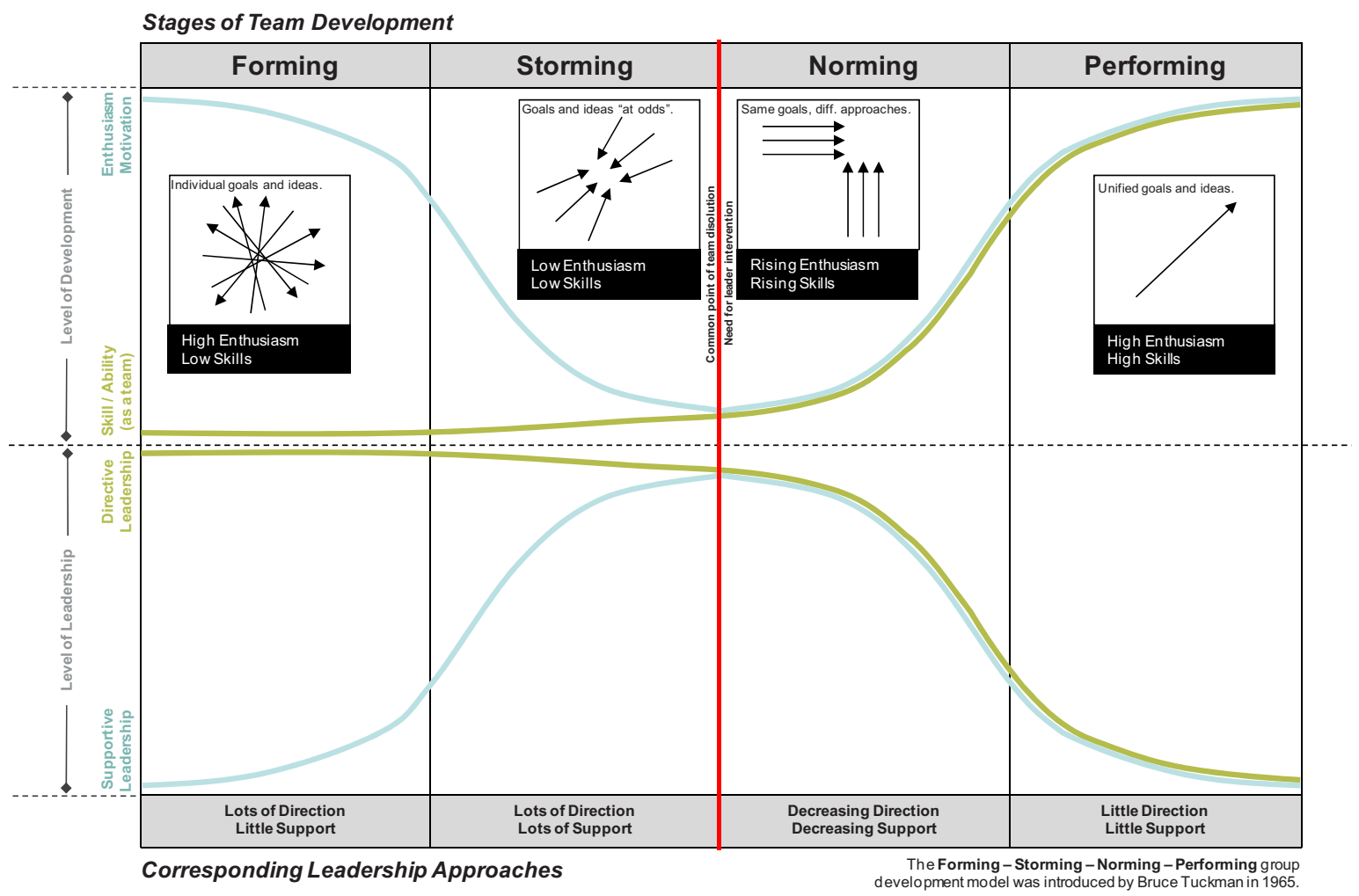

Figure 4. Stages of Team Development and Corresponding Leadership Approaches

HBDI Values Shift. As discussed above, the HBDI method of identifying and understanding individual thought preferences provides unique insight into the types of personalities and individual strengths that make teams successful. Another model developed by HBDI illustrates the Mental Path to Self-Development ${ }^{14}$ each person experiences when embracing a new skill or concept (see Figure 5), regardless of their individual "dominance" preferences. Conveniently, this "mental path" aligns perfectly with the gradual upward evolution of skill and enthusiasm experienced by teams in the Norming and Performing stage of development. As also noted above, the transition of teams from the Storming to the Norming stage is typically marked by a paradigm shift (i.e., change in the thought patterns) that drive individual behavior. This paradigm shift marks the beginning of the Mental Path to SelfDevelopment put forth by HBDI. 


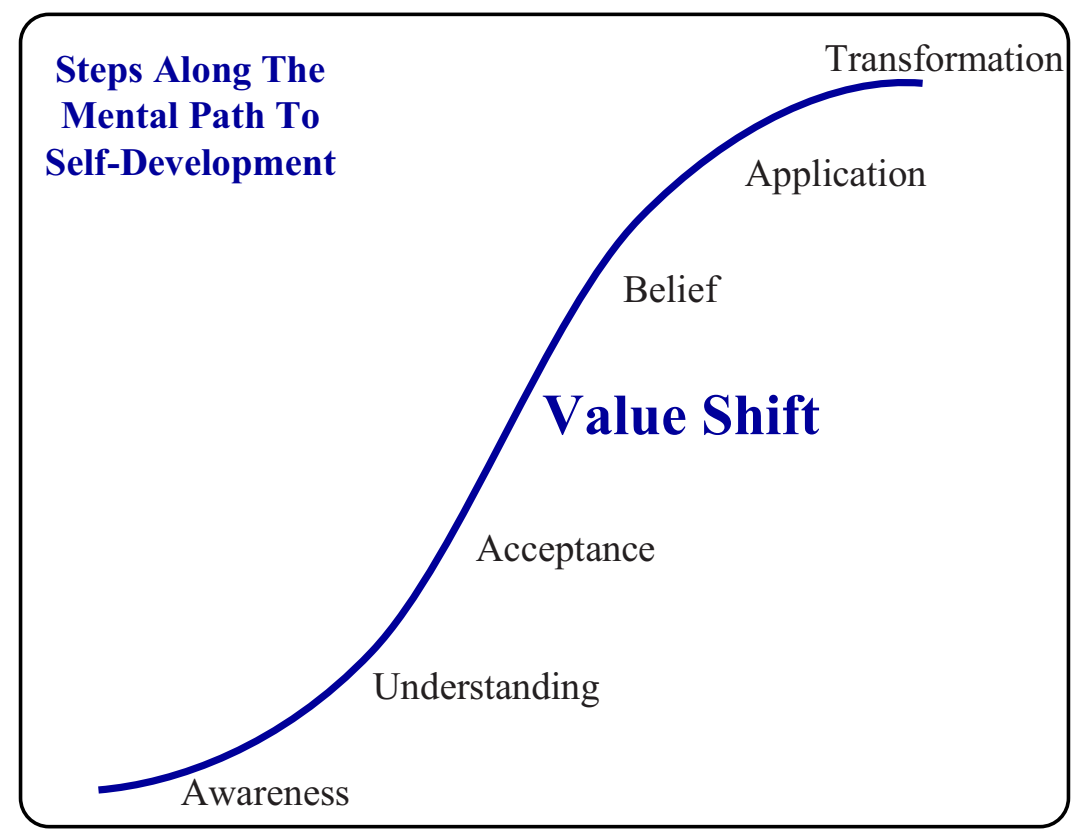

Figure 5. HBDI Mental Path to Self-Development

Once individual thought processes have changed, team members become aware of their own strengths and weakness, as well as the strengths and weakness of others. Soon they begin to understand and accept (both cognitive thought processes) their individual roles and responsibilities within the team and how those roles contribute to team success. At this stage, something deeper, more substantial begins to happen within each team member as their core values shift to accommodate a growing sense of purpose and individual responsibility and, subsequently, a higher overall level of team performance and success. This value shift marks the transition from the Norming to the Performing stages of development. Teams with an innate sense of purpose - one that is founded on the core values of its individual membersbelieve they can achieve, apply their unique skills and abilities with synergistic effect, and transform into high-performing teams.

\section{Conclusion}

If a team can reach and maintain the Performing Stage in Tuckman's Stages of Team Development, then that team has most likely become a high performance team. But that is a rare accomplishment. Most teams manage to achieve some stage of Norming and occasionally step into Performing space, but few ever transform into the type of highperformance team described here. A true high-performance team typically reflects strong extensions of basic "team" characteristics that grow out of an intense commitment to the team's mutual purpose. The qualities that distinguish a high-performance team from other ordinary teams can be summed up as follows:

High performance teams have:

- A deeper sense of purpose

- More ambitious performance goals compared to the average teams

- Better or complete approaches for resolving concerns and accomplishing work 
- Understanding and acknowledgement of their mutual accountability towards a common purpose in addition to individual obligations to their specific roles

- Complementary, and at times interchangeable, skill sets with a high degree of morale and motivation. (The Wisdom of Teams - Jon Katzenback and Douglas Smith)

As systems engineers, we need to take a new look at how we form, develop, and use IPDTs. Only through a focused effort to recognize individual personality types and skill sets (both technical and behavioral), coupled with active monitoring and guidance of team development on the part of the systems engineer, will the random groups of technical individuals that we typically assemble as "IPDTs" ever evolve to become high-performance teams capable of delivering much more than the sum of their members.

\section{Acknowledgements}

This manuscript has been authored by Battelle Energy Alliance, LLC under Contract No. DEAC07-05ID14517 with the U.S. Department of Energy. The United States Government retains and the publisher, by accepting the article for publication, acknowledges that the United States Government retains a nonexclusive, paid-up, irrevocable, world-wide, license to publish or reproduce the published form of this manuscript, or allow others to do so, for United States Government purposes.

\section{References}

1. Armstrong, T. Understanding team dynamics in the workplace. Helium, Inc. $<$ http://www.helium.com/items/114532>

2. Katzenback, J. R. and D. K. Smith. 1993. The wisdom of teams: Creating the highperformance organization. Harvard Business School Press,

3. Team dynamics - How they affect performance. Team Technology. $<$ http://www.teamtechnology.co.uk/team-dynamics.html>

4. Katzenback, J. R. and D. K. Smith. Qualities of high performance teams. Team Building. $<$ http:www.teambuildingportal.com/articles $>$

5. Rayne, I. Understanding team dynamics in the workplace. Helium, Inc. $<$. http://www.helium.com/items/1137692>

6. HBDI. Brain Dominance Models

7. A quick introduction to Belbin Team Roles. Belbin North America.

8. Miller, Diane L., The stages of group development: A retrospective study of dynamic team processes, Canadian Journal of Administrative Sciences, Jun 2003 $<$ http://findarticles.com/p/articles/mi_qa3981/is_200306/ai_n9287378/?tag=content;col1>

9. Forming, Storming, Norming and Performing, Wikipedia, February 17, 2010, $<$ http://en.wikipedia.org/wiki/Forming,_Storming,_Norming_and_Performing $>$

10. Stages of Team Development, Wood Badge for the 21st Century, Boy Scouts of America, 2005

11. Developing Your Team, National Youth Leadership Training, Boy Scouts of America, 2004

12. Richard Johnson-Sheehan, Working in Teams, Technical Communication Today, 3rd Ed., New York: Longman, 2010 p. 65-90 
13. Remember the Titans.

14. HBDI. Mental Path to Self-Development

\section{Biographies}

Margie Jeffs has over 20 years experience in business management, electrical contracting, human resources, facilitation, and training. She is currently working as a Systems Engineer at the Idaho National Laboratory (INL). She has a Bachelor of Science degree in Psychology from Idaho State University. She has a Master's Certificate in Human Performance Improvement and is currently working on her Master of Science degree in Adult and Organizational Learning, both from University of Idaho. Margie also holds other certifications in Herrmann Brain Dominance Instrument (HBDI), Associate Value Specialist (AVS), Kepner-Tregoe (KT), and Bob Pike Training Techniques. She is also a member of INCOSE.

R. Douglas Hamelin is a Systems Engineering Specialist and Technical Writer for the Idaho National Laboratory Systems Engineering Department. Mr. Hamelin is trained in requirements management and computer-aided decision support, contributes to a wide range of Systems Engineering applications as a functional analyst and document specialist, and played a major role in developing a university-accredited training course entitled Applying Systems Engineering in the DOE Environment. He supports numerous DOE projects and publications and most recently helped revise the INCOSE Systems Engineering Handbook v3.2. Mr. Hamelin received a Bachelor's degree in English from Brigham Young University in 1992 and a Master's degree in English from Idaho State University in 1994. He is an Adjunct Faculty member at Brigham Young University-Idaho and is currently preparing to take the INCOSE Certified Systems Engineering Professional (CSEP) examination. 